\title{
Formation of communicative competence through integrated forms of business communication
}

\author{
Svetlana Bylkova ${ }^{1, *}$ and Elena Chubova ${ }^{1}$ \\ ${ }^{1}$ Don State Technical University, 344003, Gagarin square 1, Rostov-on-Don, Russia
}

\begin{abstract}
The article reveals the concept content of communicative competence, as a key one, taking into account the communicative approach to the learning process. The necessity of integrating knowledge of the training modules "Business Communication", "Business Rhetoric and Corporate Culture", "Language Communication in the Professional Sphere in Russian" in the formation of the named competence is proved. The authors reveal the need for the formation of communicative competence not only in educational, but also in educational activities, where an important indicator of performance is the work of the curator. The article focuses on the role of the teacher of a higher educational institution in the process of purposeful formation of the communicative needs of students, both in terms of content and cognition. The authors show the integration mechanisms of the formation of the communicative competence of a future specialist that meets the modern needs of employers. The article reveals the content of the modules used, provides learning technologies and the results of research work.
\end{abstract}

\section{Introduction}

Communication within the educational process is one of the determining factors in the professional development of students.

The history of studying the competence-based approach in education goes back several decades. The reason for the active development of the competence model of students was the provisions of the Bologna process, among which the tasks of ensuring the quality of higher education, training based on competencies, and mastering labor skills were highlighted for all countries.

In the studies of foreign scientists, there are various approaches to both the disclosure of the concept of "competence" and to its content. In a number of works, social competence is considered as the ability to enter into meaningful interactions with other people, and the level and effectiveness of interaction depends on the context [1].

Some scientists argue the need to use a project-based teaching method, which will undoubtedly speed up the process of students mastering the entire range of professional competencies. [2].

\footnotetext{
* Corresponding author: svetbyl7592@rambler.ru
} 
It is interesting to study the educational model of the European level, based on competencies. We are talking about the need to adapt universities to the requirements of the new educational paradigm. The peculiarity is to achieve the maximum convergence of the level of competencies formed in students during training to the level of competencies dictated by the labor market [3].

The works of foreign scientists confirm the thesis that in the formation of students' communicative competence, the most successful are those teachers who themselves have a sufficient level of formation of professional competencies [4].

Many studies emphasize the importance of dialogical interaction between teachers and students, which is the key to the active formation of communicative competence [5].

\section{Materials and Methods}

Communication in a higher educational institution is characterized by an internal information exchange between all participants in the educational process. It should be noted that information flows in different directions operate in this system. In our study, we will consider two of them - vertical and horizontal. Participants of vertical communication in the educational process - teachers and students - have a significant impact on each other. Horizontal information flows can function both in the student environment and in teaching interaction.

The rapidly changing modern society makes increased demands on graduates of higher educational institutions, as specialists with an active life position, where the communicative culture takes a special place.

One of the key competencies that a graduate of any educational level and profile should possess is communicative competence, since a future specialist in his professional activity acts as an active subject of communication: he must be able to interact with various people, convince them of the fairness of his ideas, defend his professional position, be able to prevent conflicts, regulate their emotional state, etc.

The communicative competence of a specialist in any field of activity is a basic professional quality that contributes to the implementation of the goals of both an individual employee and an institution, an organization as a whole. Thus, communicative competence as a component of communicative culture seems to be a significant professional characteristic of a professional, since the implementation of production tasks also depends on the communicative qualities of the employee, his communicative skills and abilities. It is necessary to take into account the current pace of development of production, which unambiguously requires from the education system a higher rate of inclusion of new technologies, which will make it possible to prepare graduates for professional activity directly in higher educational institutions, and not at workplaces of direct employment.

Modern federal state educational standards of higher education regulate the set of competencies that should be formed in future professionals in the learning process. The bachelor's program consolidates a set of universal competencies that each student must master, among them:

- the ability to carry out social interaction and fulfill their role in the team;

- the ability to carry out business communication in oral and written forms in the state language of the Russian Federation and foreign language (s);

- the ability to manage your time, build and implement a trajectory of self-development based on the principles of self-education throughout life.

The above competences are in one way or another related to the communication process, which is a two-way exchange of information aimed at establishing mutual understanding. In Russian universities, in order to develop students' skills necessary to ensure the effectiveness of professional interaction, the discipline "Business 
Communication" is being introduced into the educational process, within which an emphasis is placed on perceptual (perception of each other by business partners), communicative (exchange of information) and interactive (interaction business communication partners) communication components. Thus, students are focused on eliminating one of the acute problems - the problem of communication, communication, manifested in a low level of empathy, frequent destructive conflicts, loneliness, psychological manipulation, difficulties in self-presentation, etc.

The teacher's task is to develop communicative competence using a variety of forms of classes and pedagogical methods that allow students to most productively master the knowledge related to the communication process, the skills of constructive and effective communication. An important role in the educational process is played by oral communication, which teachers implement when reading lecture material [6].

Competence is a special type of knowledge organization that allows you to make adequate situational decisions. This interpretation makes it possible to link competence with concepts such as constructiveness (external and internal) and performance. And communicative competence, in turn, is associated with an adequate production situation and the use of one's own experience and the experience of others. That is, it involves the synthesis of abstract knowledge and knowledge about oneself, a specific person, a specific situation.

Communicative competence, being essentially integrative, is aimed at achieving practical results in any form of business interaction, which in turn has a stimulating effect on the comprehensive development of the student's personality.

The paradigms of the modern educational system are focused on the pedagogy of cooperation, aspects of personality-oriented education and a number of others, where both the teacher and the student develop forms of joint dialogical interaction. The complex of modern pedagogical technologies allows you to purposefully form the communicative needs of students both in content and cognitive terms [7].

It is important to note that such equal activity ultimately determines equal responsibility for the end result of the learning process.

The formation of the communicative competence of students is in active connection with the use of a communicative approach, which, in turn, is implemented through solving communication problems, modeling communicative situations in teaching disciplines of the social and humanitarian profile. It is obvious that the communicative approach in education is becoming more and more in demand due to the orientation towards openness, cocreation, cooperation, and a dialogue information culture.

Taking into account the communicative approach, the learning process is built in a situation of dialogue interaction between the teacher and students, corresponding to the communicatively directed pedagogical principles. At the same time, it is important to evaluate the specifics of a specific academic discipline, its content, the logic of building individual modules, etc. The choice of means of implementing the communicative approach should be justified by age, psychological, emotional, communicative and other individual characteristics of students. So, when developing a work program for disciplines that have separate blocks for working with texts, pedagogical technologies are used that allow you to create texts that correspond to various types of professional tasks, make consistent decisions regarding the use of characteristic text properties, and maintain consistency and coherence in understanding the text [8].

Communicative competence is formed among future specialists - students of a multidisciplinary university within the framework of studying several academic disciplines (modules): "Business Communication", "Business Rhetoric and Corporate Culture", "Culture of Oral and Written Speech", "Russian Language and Culture of Speech", "Culture of speech and business communication", "Language communication in the professional 
sphere in Russian", "Language communication in the professional sphere in a foreign language". In terms of content, they are close and thematically complement each other, giving the young generation an opportunity to see an objective picture of a multifaceted phenomenon - "communicative competence". The pedagogical practice of the university has demonstrated that for the maximum efficiency of the formation and development of the above competence, it is necessary to integrate the knowledge gained in the process of implementing these modules, the basis for their formation was the work programs of the disciplines.

Note that the complementary content of various modules is the source and mechanism of integration processes in the formation of students' communicative competence.

The content of the modules: "Business Communication", "Business Rhetoric and Corporate Culture", "Language Communication in the Professional Sphere in Russian" - are designed to complement each other. So, for example, within the framework of the discipline "Business rhetoric and corporate culture" freshmen get acquainted with the essence and significance of corporate culture in a modern organization, the concept of business rhetoric and its laws, the place of business rhetoric in corporate communications, corporate ethics of the organization and the corporate code, learn about the specifics oral communications in corporate interaction. A special place is occupied by tasks focused on etiquette standards in the design of external and internal corporate correspondence. Students realize that written communication documents are a means of diagnosing the type of organizational culture of a particular organization.

In the process of teaching the discipline "Business Communication" a variety of methods are used that allow students to get an idea of the speech constructions of the species diversity of forms of business communication and indicators of speech behavior, for example, the methodology for preparing, organizing and conducting business conversations, negotiations, meetings, meetings, meetings and business meetings.

The module "Ethics in Business Communication" is of particular interest in studying the discipline. Along with basic concepts such as ethical norms of behavior, ethical formulas of treatment, students in practical classes work out ethical norms when communicating on the Internet, in various forums and chats. The transition of society to a digital format has certainly influenced interpersonal interaction. One of the new directions in the program of the discipline "Business Communication" is the ethics of business electronic correspondence. In practical classes on a designated topic, students have the opportunity to develop skills in business correspondence, the design of business letters of various contents, including accompanying letters, etc.

Within the framework of the discipline "Language communication in the professional sphere in Russian", special attention is paid to the principles of organizing speech interaction in scientific and business aspects, when using gaming technologies and problem learning technologies, where students have the opportunity to master the rules of conducting business telephone conversations, the principles of preparation and organization business meetings. The purpose of this discipline is to show the variety of forms of business communication, focusing on documentary communication. Students perform tasks related to their future professional activities: make up business letters and requests of various topics and content (informational, notification letters, etc.); prepare texts of summaries and invitations. Special attention of the student audience is focused on the language and style of paperwork, clarity and accuracy of speech, brevity of presentation and widespread use of generally accepted language formulas; correct use of lexical and graphic abbreviations. Having mastered the discipline, students come to understand that the style of the document and speech indicators help determine the type of organizational culture of a firm or institution, as well as their specific features.

When sophomores study the "Culture of Speaking and Writing" discipline, the emphasis 
is on the communicative, normative and ethical aspects of the culture of speech.

Mastering the discipline "Culture of speech and business communication" students comprehend the basics of preparing public presentations, learn about the types and types of public speaking, methods of attracting the audience's attention, barriers to information perception and ways to overcome them, various verbal and non-verbal means of communication, speech strategies and negotiation tactics, principles of preparation of meetings.

In practical classes in the form of trainings, technologies for preventing and resolving conflict situations arising in the process of professional interaction are being worked out, strategies of behavior in conflict situations are analyzed, styles of conflict resolution are considered. In addition, social and psychological trainings allows to practice the use of persuasion techniques. Active use of business games in the educational process helps students to understand strategies and tactics, methods of polemic, discussion and debate [9].

Developing communicative competence, the teaching staff actively includes skill trainings in their pedagogical practice, since they contribute to the productive formation of communicative skills and skills necessary in business communication.

Formation of emotional intelligence and meta-competence can be called the key goal of such classes. The indisputable advantage of such classroom activities is the implementation of a complex of pedagogical tasks. The most important among them, in our opinion, are: application in practice of knowledge, skills and abilities of professional interaction; awareness of the behavioral reactions of business interaction partners and the ability to analyze the manner and individual style of the interlocutor.

During the training, teachers use a three-level teaching model: acquiring knowledge and experience - demonstrating skills and acquired skills - using them in the course of imitating situations of professional communication. Thus, communication trainings affect the content of the modules.

The formation of the professional, cultural, social and practical experience of students takes place in the educational environment of the university, which, in turn, is a certain integrator of the quality of not only educational, but also educational processes.

In modern conditions, education, along with teaching, is one of the most important components of the educational process aimed at the comprehensive development of the student's personality. The changing conditions for the development of the higher education system, caused by the active introduction of information technologies, create a situation of uncertainty, which requires a person to communicate skills in solving vital problems. Thus, the student's personality needs to choose the correct communicative orientation of education.

A university teacher, along with pedagogical tasks and learning goals, sets and solves a wide range of communication tasks, where he acts as an active agent in the education of students.

The interaction "teacher - student" is a system of influences of subjects involved in joint activities on the basis of common goals of vocational education, on each other. This cooperation between teacher and student has a strong influence on the formation of the value system, including the communicative competence of the future specialist.

The fruitfulness of pedagogical interaction in higher educational institutions depends on various factors (successful determination of the goals of joint activities, teacher competence, student activity, etc.). Among them, a significant role is played by the choice of suitable teaching methods, the implementation of which will give a high level of training quality.

The interaction between teacher and student is a continuous dialogue in which they observe, reflect on each other's intentions and react to them. Both teachers and students have to make some effort for a comfortable and effective collaboration. 
The authority of a teacher consists of at least two components - the authority of the role and the authority of the individual, each of which is characterized by certain indicators. Moreover, role-based authority is one of the most important prerequisites for the formation of the authority of the teacher's personality, an important condition for the success of his pedagogical activity.

The authority of the teacher's personality is inextricably linked with such criteria as an adequate assessment of their own knowledge and skills, which in turn increases the level of understanding and interpretation of information to solve emerging problems.

When a teacher interacts with a student, it is necessary to focus on increasing the initiative of students, establishing an adequate level of understanding with them, creating a friendly atmosphere for jointly solving various kinds of problems.

The inability to analyze communicative situations, a low level of self-esteem of the actions of the participants in the interaction usually leads to the emergence of conflict situations. As practice shows, most often students indicate the injustice and bias in assessing the knowledge of students, arrogance and derogatory attitude towards students, the professional incompetence of the teacher as the reasons for conflicts with teachers.

Long ago society has come to understand the fact that the functions of a teacher in the modern educational environment are not limited exclusively to the accumulation and transmission of knowledge. It is much more important to familiarize students with a certain culture through the transfer of their own communicative experience in order to form the personality of an educated and competent specialist. To solve these problems in modern universities, there is a curatorial institute, which provides pedagogical support to students at various stages of education. The teacher-curator is constantly in interaction with student groups, solving a number of problems not only at the academic, but also at the psychological level. In the university communications system, the curator performs the function of an intermediary in the hierarchy of teacher-student interaction, which imposes additional functions on him and orientates him towards obtaining the necessary knowledge. Based on this, there is an understanding of what professional qualities a curator should have, namely, erudition, goal-setting, observation, the ability to foresee conflict situations and resolve them in a timely manner. The curator should have in his pedagogical baggage a whole set of communication tools in order to use them as effectively as possible.

Since 2003, the Don State Technical University has been operating councils of curators of faculties and the university, carrying out their activities in accordance with the Regulations on the curator of the student group. In the course of exercising its powers, the council of curators solves the tasks of defining the main directions of activity, finding ways to increase the effectiveness of educational work.

Despite the increased level of basic knowledge of modern students and the desire of students for self-education, a number of personal problems remain, the solution of which is possible only with the help of curators, mentors, and tutors. And here an important condition for effective interaction is the ability to carry out dialogue communication, which can be organized in four forms - individual, pair, group and collective. The value of dialogue interaction lies in the fact that each of the participants, realizing his own goal, thereby strives to achieve a common, joint goal, which in turn increases the level of development of individual abilities and personality traits. In addition, the key to effective communication is the observance of parity, that is, recognition of the equality of its participants as communicative individuals $[10,11]$.

The curator, building dialogical interaction with students, must observe a number of principles:

- together with students, immerse themselves in the process of self-study and selfeducation; 
- simulate situations requiring independent reflection and further solutions through their own vision of problems.

The accumulated practical experience of curatorial activity made it possible to distinguish three groups of teachers, depending on the intensity of communication with students and the nature of their interaction.

So, the first group is made up of teachers who limit their communication with students to a narrow framework of purely educational and disciplinary issues and do not seek to delve into the personal problems of students.

The second group includes teachers who strive for closer interaction with students, but do not achieve it for various reasons, including the inability to win over others.

Teachers who constantly interact with students make up the third group. As a rule, their communication is characterized by a high degree of trust and intensity. High professionalism, honesty, decency, exactingness, fairness and responsiveness are noted as important factors.

Thus, we see how the professional role of the curator is multidirectional and, therefore, complex. Consequently, curators need to acquire the necessary skills to implement them in their activities. An active platform for the development of such skills can be considered the "Hour of the Curator" classes, where conditions are formed for the comprehensive development and socialization of students through pedagogical tools, which are implemented by the teacher-curator in everyday interpersonal communication. Structurally, the program includes several modules aimed, on the one hand, at the development of general cultural speech competencies of students, on the other, at identifying and resolving the socio-psychological problems of modern youth.

When organizing classes, preference is given to innovative pedagogical technologies, which, in terms of content, are focused primarily on personal development, and not on the assimilation of new knowledge.

In particular, students are interested in interactive game teaching methods aimed at mastering the norms and rules of behavior in the educational environment when subjects interact with different social attitudes. Playing in learning contributes to the creation of various communication situations as close to reality as possible. The value of this technique lies in the formation of social experience, improving the skills of self-management of behavior, including in the event of conflicts of different orientations [12-16].

The module "The role of the curator in the formation of general cultural speech competencies of students" contains practical exercises on the development of the culture of verbal communication, techniques and methods for the development of speech competence.

As an example, consider one of the practical tasks proposed for the solution of the curators of student groups. The topic is to find out the reasons for the student's recurring late arrivals for classes. The curators were offered several options for discussing this situation, namely:

- to ask the student to write an explanatory note;

- to call the student and his parents for a conversation;

- to conduct a conversation with a student;

- to discuss the current situation in the student group.

The chosen option should be justified and reasoned. In addition, the curator must present a plan for conducting the conversation, indicate its purpose and methods for achieving it.

It should be remembered that the curator acts as an initiator in dialogical interaction, which allows him to perform a controlling function and, with the help of questions, direct the conversation in the right direction.

The task performed by the curator is discussed by all those present, if necessary, corrections and additions are made. A detailed address analysis of the advantages and 
disadvantages of the completed assignment allows the curators to come to an understanding of how and with what techniques and methods it is possible to build effective interaction with students.

Another important component in the formation of communicative competence is the passing by students of industrial and pre-diploma practice. Industrial practice, aimed at ensuring a close connection between the theoretical and practical training of students, makes it possible to gain initial experience of practical activity, creates conditions for the formation of professional competencies. The environment, as close as possible to real work activity, allows the student to evaluate the knowledge and skills acquired by him in the educational process.

\section{Results}

The levels of formation of communicative competence in students are identified in the final part of the educational process - during the on-the-job training.

Key indicators of communicative competence are measured in first year (when getting acquainted with first discipline aimed at developing communicative competence) and in fourth year after completing practical training. The results of the study are shown in Table 1.

Table.1. Measures of the level of formation of communicative competence

\begin{tabular}{|c|c|c|c|}
\hline № & $\begin{array}{c}\text { Indicators of the level of } \\
\text { communicative competence } \\
\text { formation }\end{array}$ & $\begin{array}{c}\text { Disciplines and practices } \\
\text { that form the initial level of } \\
\text { communicative competence } \\
\text { formation }\end{array}$ & $\begin{array}{c}\text { Disciplines and practices that } \\
\text { form the final level of } \\
\text { communicative competence } \\
\text { formation }\end{array}$ \\
\hline 1 & $\begin{array}{l}\text { Ability to develop and draw up } \\
\text { written business documents in } \\
\text { accordance with the current } \\
\text { regulatory and legal and } \\
\text { methodological documents }\end{array}$ & $\begin{array}{l}\text { Business communication; } \\
\text { Business rhetoric and } \\
\text { corporate culture; }\end{array}$ & $\begin{array}{l}\text { Language communication in the } \\
\text { professional field in Russian; } \\
\text { Internship }\end{array}$ \\
\hline 2 & $\begin{array}{l}\text { Ability to plan, model and } \\
\text { implement a variety of forms of } \\
\text { oral business communication }\end{array}$ & Business communication & $\begin{array}{l}\text { Culture of speech and business } \\
\text { communication; Internship; } \\
\text { Undergraduate practice }\end{array}$ \\
\hline 3 & $\begin{array}{l}\text { Ability to change the vector of } \\
\text { business communication with } \\
\text { colleagues both horizontally } \\
\text { and vertically, taking into } \\
\text { account corporate ethical norms } \\
\text { and rules }\end{array}$ & $\begin{array}{l}\text { Culture of oral and written } \\
\text { Speech }\end{array}$ & $\begin{array}{l}\text { Culture of speech and business } \\
\text { communication; Internship; } \\
\text { Undergraduate practice }\end{array}$ \\
\hline 4 & $\begin{array}{l}\text { Ability to match the positive } \\
\text { image of the organization, its } \\
\text { corporate culture }\end{array}$ & $\begin{array}{l}\text { Business rhetoric and } \\
\text { corporate culture }\end{array}$ & $\begin{array}{l}\text { Internship; Undergraduate } \\
\text { practice }\end{array}$ \\
\hline
\end{tabular}

So, the formation of the communicative competence of future specialists is carried out, on the one hand, in the study of various disciplines of a communicative orientation, on the other hand, in extracurricular activities associated with various forms of educational activities implemented at the university, and is consolidated in the process of passing various types of practices.

\section{References}

1. C. Junge, P.M. Valkenburg, M. Deković, S. Branje, The building blocks of social competence: Contributions of the Consortium of Individual Development Author links open overlay panel. Developmental Cognitive Neuroscience 45, October https://doi.org/10.1016/j.den.2020.100861 (2020) 
2. E.O. Crawford, H.J. Higgins, J. Hilburn, Using a global competence model in an instructional design course before social studies methods: A developmental approach to global teacher education. The Journal of Social Studies Research 44, 367-381 (2020)

3. Á. Rodríguez, L.E. Souto, M.L.A. Noblejas, Improving teaching capacity to increase student achievement: The key role of communication competences in Higher Education Studies in Educational Evaluation. Studies in Educational Evaluation 60, 205-213 (2019)

4. L. Zlatić, D. Bjekić, S. Marinković, M. Bojović, Development of Teacher Communication Competence Procedia - Social and Behavioral Sciences. Procedia Social and Behavioral Sciences 116, 606-610 (2014)

5. E. Câmpeanu-Sonea, A. Sonea, O.-N. Bordean, Communication Quality and Professional Competence - Evidence from a Romanian Business School. Procedia Social and Behavioral Sciences 92, 104-111 (2013)

6. A. Greculescu, L.-L. Todorescu, M.-M. Popescu-Mitroi, A.-C. Fekete, Oral Communication Competence and Higher Technical Engineering. Procedia - Social and Behavioral Sciences 128, 169-174 (2014)

7. E. Seghedin, Communication-the Main Component of Teaching Competence. Procedia - Social and Behavioral Sciences 69, 350-358 (2012)

8. Natalya Lukyanova, Yury Daneykin, Natalia Daneikina. Communicative Competence Management Approaches in Higher Education. Procedia - Social and Behavioral Sciences 214, 565-570 (2015)

9. Maria-Monica Popescu-Mitroi, Liliana-Luminita Todorescu, Anca Greculescu. The Impact of Psycho-Pedagogical Training on Communicative Competence. Procedia Social and Behavioral Sciences 191, 2443-24472 (2015) https://doi.org/10.1016/j.sbspro.2015.04.723

10. C. Stephen, C. Batson, S. Surget, J. Weller, "Student Curator Project at the University of Surrey: Encouraging and Embracing Inclusivity and Diversity Through a StaffStudent Partnership," Teaching and Learning Together in Higher Education 31 (2020) https://repository.brynmawr.edu/tlthe/vol1/iss31/6 (Last accessed 20.07.2020)

11. C.A. Smith, S. Beltman, J. Dinham, T.J. Dobinson, J. Jay Supporting Undergraduate University Students through Instrumental Mentoring. Australian Journal of Teacher Education 45(1) (2020) http://dx.doi.org/10.14221/ajte.2020v45n1.6

12. J. Ballantyne, L. Flynn, T. Olm-Madden, Problem-seeking in teacher education: Empowering students to grapple with the complexities of the profession. Australian $\begin{array}{llll}\text { Journal of } & \text { Teacher } & \text { Education (2020) }\end{array}$ http://dx.doi.org/10.14221/ajte.2020v45n5.3

13. S. Bylkova, E. Chubova, Role-playing models in the vocational education of future agribusiness experts E3S Web of Conferences 175, 15016 (2020) DOI https://doi.org/10.1051/e3sconf/202017515016

14. B. Mingzhen, A.L. Selhorst, T.T. Moore, A. Dilworth, "Enhanced Teaching Requirements: A Case Study of Instructional Growth on Student Academic Performance and Satisfaction in an Online Classroom," Journal on Empowering Teaching Excellence: 3(2), Article 3 (2019) DOI: https://doi.org/10.15142/yqvb-b327 https://digitalcommons.usu.edu/jete/vol3/iss2/3 (Last accessed 21.06.2020)

15. L. Claessens, Beginning and experienced secondary school teachers' self- and student schema in positive and problematic teacher-student relationships, Teaching and Teacher Education 55, 88-99 (2016) 
16. H. Özgan, The usage of domination strategies in conflicts between the teachers and students: A case study, Educational Research and Reviews 11(4), 146-152 URL: https://files.eric.ed.gov/fulltext/EJ1091526.pdf (Last accessed 21.06.2020) (2015) 